\title{
Articles
}

\section{Personality Functioning Scale: A Scale to Assess DSM-5's Criterion A Personality Disorders}

\author{
Juliana Beatriz Stover*a, Mercedes Fernández Liporace ${ }^{\mathrm{a}}$, Alejandro Castro Solano ${ }^{\mathrm{b}}$
}

[a] National Scientific and Technical Research Council (CONICET), Faculty of Psychology, University of Buenos Aires, Buenos Aires, Argentina. [b] National Scientific and Technical Research Council (CONICET), Faculty of Social Sciences, University of Palermo, Buenos Aires, Argentina.

\begin{abstract}
The Section III on Emerging Measures and Models included in the fifth edition of the Diagnostic and Statistical Manual of Mental Disorders, introduces a hybrid alternative approach, dimensional-categorical, to diagnose personality disorders. The Criterion A establishes the assessment of the impairment in personality functioning in terms of two dimensions: self and interpersonal. The present study was aimed at developing a short scale to measure both dimensions. The sample was composed of 342 adults from Buenos Aires city and its outskirts, with ages ranging from 19 to 82 years old $(M=39.90, S D=13.75)$. Data were gathered using the Personality Functioning Scale, developed in this study, as well as the Personality Inventory for DSM-5 Brief Form, the Mental Health Continuum Short Form, and the Symptom Check List-27. A principal components analysis conducted on 28 items found 2 factors, interpersonal and self. Internal consistency, estimated by ordinal Alphas, achieved values between .92 and .86 whilst Cronbach's Alphas were .88 and .87 . Significant and positive correlations between the Personality Functioning Scale scores on the one hand, and the Personality Inventory for DSM-5 Brief Form scores and the Symptom Check List-27 score on the other, were found. Negative correlations between PFS scores and the Mental Health Continuum Short Form were calculated. As a result, a short scale with adequate psychometric features, suitable to assess Criterion A in adult Argentinian population has been developed.
\end{abstract}

Keywords: DSM-5, personality disorders, PFS, validity, reliability

Interpersona, 2020, Vol. 14(1), 40-53, https://doi.org/10.5964/ijpr.v14i1.3925

Received: 2020-02-04. Accepted: 2020-06-05. Published (VoR): 2020-07-02

*Corresponding author at: Instituto de Investigaciones, Facultad de Psicologia, University of Buenos Aires, Hipolito Yrigoyen, 3242, 2 piso (C.P. 1225), Buenos Aires, Argentina. E-mail: julianastover@psi.uba.ar

This is an open access article distributed under the terms of the Creative Commons Attribution 4.0 International License, CC BY 4.0 (https://creativecommons.org/licenses/by/4.0/), which permits unrestricted use, distribution, and reproduction in any medium, provided the original work is properly cited.

Criteria used to diagnose personality disorders (PD) have been extensively criticised in the succeeding editions of the Diagnostic and Statistical Manual of Mental Disorders (DSM). Among these objections, the lack of theoretical and empirical support for the delimitation of the PD's 10 categories stands out as a major issue. That lack of evidence generated clinical issues for practitioners, such as difficulties to describe an individual's singularity using a unique diagnostic category. These issues led to an increase of cases labelled as unspecified PD, along with high comorbidity rates (e.g., Hopwood et al., 2011; Krueger et al., 2011). As a result, DSM-5 (American Psychiatric Association, 2013a) added the Section III, referred to Emerging Measures and Models. Among these models, an alternative approach to diagnose PDs, differing from the traditional categorical classification comprised in Section II was introduced. Such new approach includes criteria based on a hybrid dimensional-categorical model. On the one hand, the goal is to achieve a categorical diagnose of six PDs on 
the grounds of several dimensions defined by Criterion A and Criterion B. On the other hand, the continuity of the adaptive and pathological personality represents the core of this approach, therefore making it useful to describe community population.

Criterion A suggests analysing the levels of impairment in personality regarding both self and interpersonal functioning. As for the self functioning, two areas are taken into account: 1) identity, characterised by neat boundaries between the self and other persons, a sound self-esteem, and an appropriate regulation of emotions, and, 2) self-direction, which implies seeking realistic goals, according to prosocial and constructive behaviours, as well as the ability to be self-reflective. Concerning the interpersonal functioning, it encompasses: 1) empathy, involving the ability to understand and sympathise with other people's feelings, as well as being aware of the impact of the own behaviour in other persons' lives, and 2) intimacy, linked to the desire of bonding and the development of close and mutual relationships.

Criterion B introduces 25 pathological personality trait facets, grouped into five trait domains: negative affectivity - experiencing negative emotions and their behavioural outcomes, detachment - avoiding interaction with others and restricting emotional experience, antagonism - behaving in a way that causes conflict with others, always acting to take advantage, disregarding people's needs and feelings due to an egotistic attitude, disinhibition - impulsive behaviour aimed at immediate satisfaction, and psychoticism - eccentric behaviour and ideation compared to those which are common in the cultural environment where the individual was raised.

Due to the fact that the Personality Inventory for DSM-5 (PID-5; American Psychiatric Association, 2013b; Krueger, Derringer, Markon, Watson, \& Skodol, 2012) was developed to measure Criterion B, it has drawn more attention than Criterion A. PID-5 also has two short forms (e.g. American Psychiatric Association, 2013c; Góngora \& Castro Solano, 2017b; Maples et al., 2015), and an informant-report version (PID-5-IRF; Markon, Quilty, Bagby, \& Krueger, 2013), whose psychometric features were examined in various studies (e.g., Al-Dajani, Gralnick, \& Bagby, 2016; Zimmermann, Kerber, Rek, Hopwood, \& Krueger, 2019).

Although many measures of Criterion A have been developed, results regarding their structure are not conclusive. Moreover, none of these measures was developed taking into account the Latin American culture or the Spanish language. DSM-5 introduces the Level of Personality Functioning Scale (LPFS), which entails the description of the four dimensions above mentioned (identity, self-direction, empathy, intimacy) according to different levels of severity, ranked from "little or no impairment" to "extreme" level of impairment. Following such descriptions, clinicians must estimate the severity of the examinee's symptoms. The LPFS first validity evidences analysis was conducted by Bender, Morey, and Skodol (2011). LPFS's utility as a diagnostic method has been verified, no matter the expertise of the examiner (e.g., Buer Christensen et al., 2018; Zimmermann et al. 2014, 2015). Additionally, it is worth mentioning that self-report measures developed to assess Criterion $A$ are scarce and incipient (Zimmermann et al., 2019).

The pioneer studies were performed in Germany, where Hutsebaut, Feenstra, and Kamphuis (2016) developed the Level of Personality Functioning Scale-Brief Form (LPFS-BF), composed of 12 items. A principal components analysis found a structure representing the Self-Functioning and the Interpersonal Functioning dimensions (35.2\% of explained variance), with internal consistency values of $\alpha=.57$, and $\alpha=.65$. Moreover, patients obtained significantly higher scores compared to a community sample. Convergent validity evidences with the Brief Symptom Inventory (BSI; de Beurs \& Zitman, 2006), which is a general measure of pathology, were also analysed. The correlation between the LPFS-BF and the BSI scores achieved an $r=.51$ for Self- 
Functioning, whilst Interpersonal Functioning obtained $r=.38$. Later on, Weekers, Hutsebaut, and Kamphuis (2019) developed the LPFS-BF 2.0 on the basis of LPFS-BF. This new scale presents alterations in 3 items as well as in the response scale, to make it alike the PID-5. A confirmatory factor analysis conducted on a clinical sample verified the same factors which were found in the previous principal components analysis. The association between factors was moderate $(r=.44)$.

Morey (2017) developed the Level of Personality Functioning Scale-Self Report (LPFS-SR). It includes 80 items assessing the four dimensions composing Criterion A. Studies on psychometric features were performed on an American sample. A principal components analysis using the four scores as input variables found a unique factor explaining $85.5 \%$ of the variance. Such factor was identified as a global dimension of impairment, feasible to be observed in the intrapersonal or/and the interpersonal sphere. This global impairment score obtained high correlation coefficients $(r=.72$, and $r=.85)$ with several measures of personality disorders, such as the General Assessment of Personality Disorder (GAPD; Livesley, 2009), and the General Personality Pathology Scale (GPP; Morey et al., 2011). As for the internal consistency, Cronbach's Alpha coefficients were .96 for the total score and ranged from .81 to .89 for the dimensions. Hopwood et al. (2018) followed Morey's studies (Morey, 2017), replicating the principal components analysis, finding a unique factor as well. The scale's internal consistency was $\alpha=.92$, with coefficients ranging from .92 to .80 regarding the four dimensions. Correlations between LPFS-SR and the dimensions composing the Big Five Inventory-2 (Soto \& John, 2017) were significant. Neuroticism obtained high correlations with the LPFS-SR total score $(r=.60)$, with the Self Domain $(r=.67)$, and with the Interpersonal Domain $(r=.47)$. Conscientiousness, Agreeableness, Extraversion, Openness obtained negative values with both domains and with the LPFS-SR total score $(-.30$ to -.58). The analysis of the link between Criterion A and Criterion B showed that 18 out of the 25 PID-5 pathological personality trait facets reached correlations higher than .50 with the LPFS-SR dimensions.

Also in the United States, this time analysing a clinical sample, Huprich et al. (2018) developed the DSM-5 Levels of Personality Functioning Questionnaire (DLOPFQ), composed of 132 items assessing the 4 dimensions that were introduced in the DSM-5. Such 4 dimensions were afterwards divided into the Social and Work subscales, leading to 8 different scores. Results showed an internal consistency with Cronbach's Alphas between .72 and .80 . Every scale was positively correlated with the scales composing the short version of PID-5, with Pearson's $r$ indices from .21 to .70 . Associations between the 8 dimensions of DLOPFQ with Antagonism and Detachment were high. Negative associations with the Swartz Outcome Scale-10 (SOS-10; Baity, Kehl-Fie, \& Blais, 2009), which assesses psychological well-being, were also found (between -.25 and -.59). Further studies on DLOPFQ raised the question about the pertinence of dividing the 4 areas (Self-Direction, Identity, Intimacy, Empathy) into Social and Work subscales, therefore considering 8 scores (Nelson et al., 2018). After that, they developed a short version (DLOPFQ-SF), selecting 24 items following expert advice. An exploratory factor analysis conducted on a sample of patients and non-patients found a 4-factor structure explaining $52.9 \%$ of the variance. Since some items loaded on two factors, a 1-factor, a 2-factor and a 3-factor model were tested by confirmatory factor analyses. Findings showed a better fit for the 4-factor model, even though items with double loadings were admitted. Correlations with psychological well-being, measured by SOS-10, obtained negative coefficients (Pearson's $r$ from -.24 to -.56). Internal consistency was adequate ( $\alpha$ $=.73 / \alpha=.96)$.

The Self and Interpersonal Functioning Scale (SIFS) is another example of a test to measure Criterion A. It was developed by Gamache, Savard, Leclerc, and Côté (2019), and the psychometric analyses were performed 
on Canadian community and clinical samples. A 4-factor-24-item model was confirmed by the factor analysis procedure. A second-order analysis obtained one general personality pathology factor. Regarding the scores' reliability, Cronbach's Alphas indicating internal consistency ranged from .60 to .92, and stability reliability found Pearson's $r$ coefficients between .63 and .91. Significant differences in items' scores by group (community sample versus clinical sample) were verified, except for two items. However, authors maintained such items in the final version of the scale. Besides, correlations between SIFS' scores and the Criterion B domains, measured by PID-5, were positive and high $(r=.49$ to $r=.81)$.

Finally, the unique study conducted on adolescents (12 to 18-year-old children) deserves a special mention (Goth, Birkhölzer, \& Schmeck, 2018). It developed the Levels of Personality Functioning (LoPF-Q 12-18), composed of 97 items, whose features were analysed on clinical and community samples from Switzerland, Austria, and Germany. Exploratory factor analysis reported a 4 -factor structure explaining $39.9 \%$ of the variance. Most of the items (72.2\%) showed loadings higher than .30 in only one factor. Statistically significant differences were found in average scores obtained by a clinical sample versus a school sample. Internal consistency ranged from .76 to .92 . Table 1 summarises features of the scales above mentioned.

Table 1

Scales Developed to Assess Criterion A

\begin{tabular}{|c|c|c|c|c|c|c|c|}
\hline Author & Scale & Country & Participant & Item & Factor & $\begin{array}{l}\text { Type of factor } \\
\text { analysis }\end{array}$ & $\alpha$ \\
\hline Hutsebaut et al. (2016) & LPFS-BF & Netherlands & 240 adults (patients) & 12 & 2 & PCA & $.57 / .65$ \\
\hline Weekers et al. (2019) & LPFS-BF 2.0 & Netherlands & 229 adults (patients) & 12 & 2 & CFA & - \\
\hline Morey (2017) & LPFS-SR & EEUU & 306 adults (community) & 80 & 1 & PCA & .96 \\
\hline Hopwood et al. (2018) & LPFS-SR & EEUU & 1976 adults (community) & 80 & 1 & PCA & .92 \\
\hline Huprich et al. (2018) & DLOPFQ & EEUU & 140 adults (patients) & 132 & 8 & - & $.72 / .80$ \\
\hline Siefert et al. (2019) & DLOPFQ-SF & EEUU & $\begin{array}{c}500 \text { adults (community), } \\
135 \text { adults (patients), } \\
644 \text { adults (college students) }\end{array}$ & 24 & 4 & $\begin{array}{l}\text { EFA } \\
\text { CFA }\end{array}$ & $.73 / .96$ \\
\hline Gamache et al. (2019) & SIFS & Canada & $\begin{array}{l}280 \text { adults (community), } \\
106 \text { adults (patients) }\end{array}$ & 24 & 4 & CFA & $.60 / .92$ \\
\hline Goth et al. (2018) & LoPF-Q 12-18 & $\begin{array}{c}\text { Switzerland, Austria, } \\
\text { Germany }\end{array}$ & $\begin{array}{l}351 \text { adolescents (students) } \\
415 \text { adolescents (patients) }\end{array}$ & 97 & 4 & EFA & $.76 / .92$ \\
\hline
\end{tabular}

Note. $\mathrm{PCA}=$ principal component analysis; EFA = exploratory factor analysis; CFA = confirmatory factor analysis.

The scales previously described present an inconvenient to be highlighted. On the one hand, the diversity of dimensions found by different authors did not reach consensus on the measurement of Criterion A. On the other hand, no scale has been designed taking into consideration the specificities of the Spanish language. Furthermore, Latin America shows a lack of studies analysing Criterion A or developing measures of it. As a matter of fact, only scales assessing Criterion B are available for clinicians and researchers (e.g., Góngora \& Castro Solano, 2017b; Stover, Castro Solano, \& Fernández Liporace, 2019). As a result, this study is aimed 
at developing a scale to measure personality functioning in terms of the self and interpersonal dimensions introduced in DSM-5. It is also aimed at analysing its psychometric features in order to make the scale suitable to be used in local population.

\section{Method}

\section{Design}

A non-experimental and cross-sectional design was conducted.

\section{Participants}

A non-probabilistic sampling was employed. 342 adults from Buenos Aires city and its outskirts ( $50 \%$ females, $50 \%$ males) with ages between 19 and 75 years old $(M=39.90, S D=13.75)$ participated. Most of them had a job (78.9\%). The remaining percentages were as follows: housewives/househusbands (4.4\%), retired (5\%), unemployed looking for a job (4.7\%), and unemployed not looking for a job (7\%). As for educational qualifications, high school graduates represented the higher percentage, with $48.9 \%$ whilst $44 \%$ were college graduates. Smaller percentages corresponded to the ones graduated from Elementary school (6.7\%), and those who dropped that educational stage $(0.3 \%)$.

\section{Material}

\section{Sociodemographic Survey}

It gathers information on gender, age, educational status, and occupation.

\section{Personality Functioning Scale (PFS)}

28 items to assess impairment in personality regarding self and interpersonal functioning were developed. A 4-point Likert response scale from Totally false to Very true was employed.

\section{Personality Inventory for DSM-5 Brief Form (PID-5-BF)}

The short local and adapted version of PID-5-BF (Góngora \& Castro Solano, 2017b) is composed of 25 items using a 4-point Likert response from Very false or Often false to Very true or Often true. Five major domains are measured: Negative Affectivity, Disinhibition, Detachment, Antagonism, Psychoticism. An exploratory factor analysis found five factors. Their internal consistency ranged between $\alpha=.86$ to $\alpha=.90$.

\section{Mental Health Continuum Short Form (MHC-SF)}

MHC-SF (Keyes, 2005; Lupano Perugini, de la Iglesia, \& Castro Solano, 2017) is composed of 14 items assessing Emotional, Social and Psychological Well-being. It also includes a total score indicating the examinee's positive mental health. Emotional Well-being coincides with the hedonic well-being, whilst the other two dimensions correspond to eudemonic well-being. Items include a 5-point Likert response, from Never to Every day. A confirmatory factor analysis found three factors with adequate internal consistency indices $(\alpha=.78, \alpha$ $=.89)$. 


\section{Symptom Check List 27 (SCL-27)}

SCL-27 (de la Iglesia \& Castro Solano, 2019; Hardt \& Gerbershagen, 2001) is a short version of the SCL-90-R (Casullo \& Pérez, 2008; Derogatis, 1983). It is composed of 27 items responded by a 5-point Likert scale (Not at all to Extremely), assessing psychopathological unspecified symptoms suffered in the last week. Its 1-dimension structure was verified by a confirmatory factor analysis, and its internal consistency, estimated by Cronbach's Alpha was .92.

\section{Procedure}

Considering previous studies and the DSM- 5 guidelines, items to assess impairments in personality functioning in terms of self and interpersonal domains were developed. Five experts examined those items following recommendations for short scales' development (Stanton, Sinar, Balzer, \& Smith, 2002). 28 items were selected according to how well they met DSM-5's criteria (American Psychiatric Association, 2013a). Later, a pilot study, aimed at examining the items clarity, was run with 20 adults. Although all of the items remained, a few minor modifications in the statements were made. The Appendix contains the version developed in Spanish.

After conducting the procedures above described, data were gathered in individual sessions. Psychology undergraduates collaborated under the supervision of trained psychologists. Participants volunteered and no retribution was given, neither economical nor academic. An informed consent signed by the participants guaranteed confidentiality of results and anonymity. Participants were told about the feasibility of ceasing participation at any moment of the process. Eight answer sheets, which showed many non-responded items were left out.

\section{Data Analysis}

Construct validity evidences of the scale were examined by means of a minimum rank factor analysis. A polychoric covariance matrix was employed since the response scale was ordinal (Muthén \& Kaplan, 1985). Ordinal Alpha coefficients were calculated to estimate internal consistency of scores (Elosúa \& Zumbo, 2008). Such analyses were conducted using the FACTOR software (Lorenzo-Seva \& Ferrando, 2013). Additionally, Cronbach's Alphas were also determined. The Attenuation Index was used to estimate which percentage of the theoretical internal consistency decreased when Cronbach's Alpha was calculated (Dominguez-Lara, 2018).

Pearson's $r$ coefficients between the scale's scores, the short version of the PID-5 scores, the SCL-27 score and de MHC score were calculated, in order to analyse criterion validity evidences. The effect sizes of the correlations were examined regarding the following cut-off points: small $=.10$, medium $=.30$, large $=.50$ (Cohen, 1988). Such calculations were run employing PASW Statistics for Windows, Version 18.0 (SPSS, 2009).

\section{Results}

\section{Construct Validity}

A minimum rank factor analysis with a direct oblimin rotation was performed, in order to examine construct validity evidences. Prior to that, a polychoric correlations matrix was generated. The parallel analysis method (Horn, 1965) suggested the retention of two factors. Items 14 and 27 were excluded since they showed 
cross-loadings that are less than .10 , different from the loading on the factor of interest. The sample size was adequate for the calculations which were performed $\left(\mathrm{KMO}=.923\right.$; Bartlett's Sphericity Test: $\mathrm{X}^{2}=3389.1$, $d f=325 ; p<.01)$. The explained total variance was $51.33 \%$, mostly by the first factor $(43.73 \%)$, whereas the second factor explicative percentage was, comparatively, much lower (7.59\%). Regarding the content of the items, factors were identified as Interpersonal (F1) and Self (F2). Table 2 shows factorial loadings higher than .40 in bold. The correlation between factors was positive and large $(r=.663 ; p<.01)$.

Table 2

PFS Factorial Loadings

\begin{tabular}{|c|c|c|}
\hline Item & F1 & $\mathbf{F 2}$ \\
\hline 1. Close relationships rarely end up well. & .753 & .061 \\
\hline 3. Even though I try, I'm not able to maintain long-term successful relationships. & .627 & .116 \\
\hline 5. I don't care much about having close relationships. & .910 & -.109 \\
\hline 7. Since close relationships make me feel helpless, they aren't worth the risk. & .717 & .101 \\
\hline 9. I could only bond closely with someone able to perceive and respond to my needs. & .510 & .016 \\
\hline 11. I can't stand when someone has an opinion quite different from mine. & .554 & .147 \\
\hline 13. I can't understand why people act in the way they do. & .652 & -.010 \\
\hline 15. I seldom have many pleasant or positive interactions with people. & .795 & -.023 \\
\hline 17. I don't care about the consequences of my actions that might affect other people. & .816 & -.099 \\
\hline 19. I don't have a clue about other people's intentions. & .656 & .047 \\
\hline 21. Many people have harmful intentions. & .464 & .250 \\
\hline 23. Relationships are often painful, and they also make me suffer. & .588 & .285 \\
\hline 25. Every now and then, ignoring the outcomes of my behaviour on others is easy for me. & .612 & .068 \\
\hline $\begin{array}{l}\text { 2. Understanding the distinction between what I think and what others expect me to think can be } \\
\text { hard for me. }\end{array}$ & .085 & .619 \\
\hline 4. It's hard for me to set my own personal goals. & .086 & .646 \\
\hline $\begin{array}{l}\text { 6. I am a spur-of-the-moment kind of person, so I don't usually focus on long-term desires and } \\
\text { plans. }\end{array}$ & -.133 & .723 \\
\hline 8. Generally, I feel awesome or awful about myself. & .031 & .687 \\
\hline 10. Looking back impartially at my life is hard for me. & .155 & .489 \\
\hline 12. I have doubts about the standards I should follow in my behaviour. & .140 & .671 \\
\hline 16. I experience fast changes of emotions. & .098 & .604 \\
\hline 18. The values guiding my behaviour always depend on the situation. & .005 & .642 \\
\hline 20. My personal standards are usually too high or too low. & .009 & .734 \\
\hline 22. Some of my personality features don't match with each other. & -.014 & .784 \\
\hline 24. I get either furious or embarrassed when I don't pull things off. & -.132 & .612 \\
\hline 26. When I accomplish something, I think I'm a fake. & .250 & .559 \\
\hline 28. It is hard for me to control my emotions when people judge me. & -.053 & .779 \\
\hline
\end{tabular}

Note. Factorial loadings higher than .40 are shown in bold.

\section{Internal Consistency}

Internal consistency was adequate either when it was calculated by ordinal Alphas or when Cronbach's Alphas were used, resulting higher with the former (Table 3). The Attenuation Index was below 30\% (Dominguez-Lara, 2018). That indicates that both Alpha coefficients are dependable. 
Table 3

PFS Internal Consistency

\begin{tabular}{lccc}
\hline Scale & Ordinal Alpha & Cronbach's Alpha & Attenuation index \\
\hline Interpersonal & .92 & .88 & $4 \%$ \\
Self & .86 & .87 & $1 \%$ \\
\hline
\end{tabular}

\section{Criterion Validity}

Positive and large associations among the five PID-5 BF domains and the PFS dimensions were found, except for the association between the Interpersonal dimension and the Negative Affectivity dimension, which was medium. As for SCL-27 score, positive associations were reported: medium with the PFS Interpersonal dimension and large with the PFS Self dimension. The correlations between PFS scores and the MHC scores were significant and negative. They were small with Social Well-being and moderate with the remaining ones (Table 4).

Table 4

PFS, PID-5 BF, SCL-27, MHC Correlations

\begin{tabular}{|c|c|c|}
\hline Dimension & Interpersonal & Self \\
\hline Negative affectivity & $.272^{* *}$ & $.512^{* \star}$ \\
\hline Detachment & $.625^{\star \star}$ & $.544^{* *}$ \\
\hline Antagonism & $.495^{\star \star}$ & $.496^{* *}$ \\
\hline Disinhibition & $.441^{\star *}$ & $.551^{\star *}$ \\
\hline Psychoticism & $.495^{\star *}$ & $.570^{* *}$ \\
\hline SCL-27 & $.353^{\star *}$ & $.570^{* *}$ \\
\hline Emotional well-being & $-.432^{* \star}$ & $-.419^{\star *}$ \\
\hline Social well-being & $-.123^{*}$ & $-.153^{*}$ \\
\hline Psychological well-being & $-.343^{* *}$ & $-.388^{* *}$ \\
\hline Total well-being & $-.329^{* *}$ & -.326 \\
\hline
\end{tabular}

${ }^{*} p<.05 .{ }^{* *} p<.01$.

\section{Discussion}

The study was aimed at developing a short scale to assess impairments in personality according to the Criterion A introduced in the DSM-5's Section III (American Psychiatric Association, 2013a). Based on Morey's studies (Morey, 2017) and following Stanton's recommendations for short scales' development (Stanton et al., 2002), 28 items were examined by a minimum rank factor analysis, obtaining a 26 -item-2-factor structure. The exam of the content of the items composing the factors suggested that there is a correspondence between the impairment dimensions related to the Self and to the Interpersonal Relationships. The number of factors has been a controversial issue since 1-factor, 2-factor, 4-factor and 8-factor structures were reported (e.g., Zimmermann et al., 2019). DSM-5 introduces two major dimensions (Self and Interpersonal). The Self-Functioning one is composed of two lower rank dimensions (Identity and Self-Direction), whilst the Interpersonal Functioning major dimension involves the Empathy and Intimacy minor dimensions. However, such classification was only verified by Goth et al. (2018) and Gamache et al. (2019). 
The present study, like those conducted by Hutsebaut et al. (2016) and Weekers et al. (2019), found two factors, following the estimations of the parallel analysis (Horn, 1965). Besides, the fact that double factorial loadings were absent must be highlighted since such issue had been negatively pointed out by Goth et al. (2018) and Siefert et al. (2019) about their results. Consequently, construct validity evidences for the PFS scale seem adequate since they are theoretically coherent with DSM-5, and because of the psychometric quality of the items as well. Although two factors were found, the correlations between them were large. Hence, further confirmatory studies should examine the likelihood of a unique underlying factor as reported by Morey (2017) and Hopwood et al. (2018).

Regarding scores' reliability, internal consistency was estimated by means of two statistics: Cronbach's Alpha, following previous studies, and ordinal Alpha coefficients which is more appropriate since data were ordinal. Both estimators reached adequate values (Cortina, 1993). Such result represents an improvement regarding previous studies run on short scales, where those coefficients were barely up to 65 (e.g., Gamache et al., 2019; Hutsebaut et al., 2016).

As for criterion validity evidences, correlations between EFP and PID-5-BF were large. Significant and high values verify the link between Criterion $A$ and Criterion $B$. Such results are reasonable since they correspond to the main criteria to diagnose PDs according to the DSM-5's Section III. These findings add strength to the evidence previously reported by Hopwood et al. (2018) and by Gamache et al. (2019) about correlations higher than .50 between scales measuring Criterion A and Criterion B. Associations between SCL-27 score and the EFP major dimensions scores were analysed. Pearson's $r$ with the EFP Self dimension score was large, whilst it was medium regarding EFP Interpersonal dimension score. Two issues should be underlined. On the one hand, the SCL-27's items content does not assess symptoms involving interpersonal relationships. On the other, values follow the same correlational pattern between LPFS-BF and BSI scores (BSI is a scale similar to SLC-27; Hutsebaut et al., 2016). Beyond the differences among the values achieved by Pearson's $r$ coefficients between PFS dimensions scores and the SCL-27 score, evidence supporting the link between psychopathological distress experienced during the last week and personality dysfunctions was verified. The PFS obtained negative correlations with the MHC scores. As reported by Huprich et al. (2018) and Siefert et al. (2019), psychological well-being is usually the opposite pole of impairments in personality functioning.

About the weaknesses of the study, the use of a convenience community sample restricts the conclusions' generalisation. Even though DSM-5 (American Psychiatric Association, 2013a) states that the dimensional model is useful to assess either individuals from the community population or suffering from personality dysfunctions, adding a clinical sample would have been optimal in order to test such assertion. Besides, even when the answer sheets were carefully reviewed, the lack of validity scales arises as an issue since it might generate biased responses.

As regards of the limitations above described and taking into consideration that DSM- 5 was originally aimed at diagnosing psychopathological disorders, further studies should be focused on analysing psychometric features of the PFS in clinical samples. Replicating the studies on the structure of the scale in other countries in Latin America would also be a matter of interest, as well as the development and adaptation of such scale in other languages.

In sum, a scale to assess Criterion A, suitable to be used in local population given their linguistic adaptation to the Spanish spoken in Argentina, with adequate validity evidences and appropriate reliability results has been 
developed. This is the first scale in Spanish developed to assess Criterion A, as a first step in the analysis of the new model to assess PDs presented in the DSM-5's Section III (American Psychiatric Association, 2013a). From the methodological standpoint, the ordinal nature of items was taken into consideration, calculating polychoric correlational matrices and ordinal Alphas, thus ameliorating previous studies' weaknesses. As for clinicians, 28 items enable shorter testing sessions as well as easier and faster scoring processes compared to longer versions, involving from 80 to 132 items (e.g., Hopwood et al., 2018; Huprich et al., 2018; Morey, 2017). The theoretical contribution here presented, referred to the emerging models introduced in DSM-5 deserves to be pointed out since the notion of impairments in personality functioning according to Criterion $A$ has been analysed in a Latin American sample for the first time.

\section{Funding}

The authors have no funding to report.

\section{Competing Interests}

The authors have declared that no competing interests exist.

\section{Acknowledgments}

The authors have no support to report.

\section{References}

Al-Dajani, N., Gralnick, T. M., \& Bagby, R. M. (2016). A psychometric review of the personality inventory for DSM-5 (PID-5): Current status and future directions. Journal of Personality Assessment, 98(1), 62-81. https://doi.org/10.1080/00223891.2015.1107572

American Psychiatric Association. (2013a). Diagnostic and statistical manual of mental disorders (DSM-5). Washington, DC, USA: American Psychiatric Pub.

American Psychiatric Association. (2013b). The personality inventory DSM-5 (PID-5) self-report form [full version]. Retrieved from https://www.psychiatry.org/psychiatrists/practice/dsm/educational-resources/assessment-measures\#Personality

American Psychiatric Association. (2013c). The personality inventory for DSM-5-Brief Form (PID-5-BF)-Adult. Retrieved from https://www.psychiatry.org/psychiatrists/practice/dsm/educational-resources/assessment-measures\#Personality

Baity, M., Kehl-Fie, K., \& Blais, M. A. (2009). Schwartz Outcome Scale-10: A brief measure of psychological well-being. Patient Reported Outcomes, 39, 19-21.

Bender, D. S., Morey, L. C., \& Skodol, A. E. (2011). Toward a model for assessing level of personality functioning in DSM-5, Part I: A review of theory and methods. Journal of Personality Assessment, 93(4), 332-346. https://doi.org/10.1080/00223891.2011.583808

Buer Christensen, T., Paap, M. S. C., Arnesen, M., Koritzinsky, K., Nysaeter, T., Eikenaes, I., .. . Hummelen, B. (2018). Interrater reliability of the structured clinical interview for the DSM-5 alternative model of personality disorders module i: 
Level of personality functioning scale. Journal of Personality Assessment, 100(6), 630-641.

https://doi.org/10.1080/00223891.2018.1483377

Casullo, M. M., \& Pérez, M. (2008). El Listado de Síntomas SCL-90-R de Derogatis [Derogatis SCL-90-R symptom list]. Buenos Aires, Argentina: Departamento de Publicaciones, Facultad de Psicología, UBA.

Cohen, J. (1988). Statistical power analysis for the behavioral sciences (2nd ed.). Hillsdale, NJ, USA: LEA.

Cortina, J. M. (1993). What is coefficient alpha? An examination of theory and applications. The Journal of Applied Psychology, 78(1), 98-104. https://doi.org/10.1037/0021-9010.78.1.98

de Beurs, E., \& Zitman, F. (2006). De Brief Symptom Inventory (BSI): De betrouwbaarheid en validiteit van een handzaam alternatief voor de SCL-90 [The Brief Symptom Inventory (BSI): The reliability and validity of a handy alternative to the SCL-90]. Maandblad Geestelijke Volksgezondheid, 61, 120-141.

de la Iglesia, G., \& Castro Solano, A. (2019). Academic achievement of college students: The role of the positive personality model. Problems of Education in the 21st Century, 77(5), 572-583. https://doi.org/10.33225/pec/19.77.572

Derogatis, L. R. (1983). Symptom checklist-90-revised. San Antonio, TX, USA: Pearson.

Dominguez-Lara, S. (2018). Fiabilidad y alfa ordinal [Reliability and ordinal alpha]. Actas Urologicas Espanolas, 42(2), 140-141. https://doi.org/10.1016/j.acuro.2017.07.002

Elosúa, P., \& Zumbo, B. D. (2008). Coeficientes de confiabilidad para escalas de respuesta categórica ordenada [Reliability coefficients for ordinal categorical response scales]. Psicothema, 20(4), 896-901.

Gamache, D., Savard, C., Leclerc, P., \& Côté, A. (2019). Introducing a short selfreport for the assessment of DSM-5 level of personality functioning for personality disorders: The Self and Interpersonal Functioning Scale. Personality Disorders, 10(5), 438-447. https://doi.org/10.1037/per0000335

Góngora, V. C., \& Castro Solano, A. (2017a). Assessment of the mental health continuum in a sample of Argentinean adults. Psychology, 8, 303-318. https://doi.org/10.4236/psych.2017.83018

Góngora, V. C., \& Castro Solano, A. (2017b). Pathological personality traits (DSM-5), risk factors, and mental health. SAGE Open, 7(3), 1-10. https://doi.org/10.1177/2158244017725129

Goth, K., Birkhölzer, M., \& Schmeck, K. (2018). Assessment of personality functioning in adolescents with the LoPF-Q 1218 Self-Report Questionnaire. Journal of Personality Assessment, 100(6), 680-690.

https://doi.org/10.1080/00223891.2018.1489258

Hardt, J., \& Gerbershagen, H. U. (2001). Cross-validation of the SCL-27: A short psychometric screening instrument for chronic pain patients. European Journal of Pain, 5(2), 187-197. https://doi.org/10.1053/eujp.2001.0231

Hopwood, C. J., Good, E. W., \& Morey, L. C. (2018). Validity of the DSM-5 levels of Personality Functioning Scale-Self Report. Journal of Personality Assessment, 100(6), 650-659. https://doi.org/10.1080/00223891.2017.1420660

Hopwood, C. J., Malone, J. C., Ansell, E. B., Sanislow, C. A., Grilo, C. M., Mcglashma, T. H., . . Morey, L. C. (2011). Personality assessment in DSM-5: Empirical support for rating severity, style, and traits. Journal of Personality Disorders, 25(3), 305-320. https://doi.org/10.1521/pedi.2011.25.3.305 
Horn, J. L. (1965). A rationale and test for the number of factors in factor analysis. Psychometrika, 30(2), 179-185. https://doi.org/10.1007/BF02289447

Huprich, S. K., Nelson, S. M., Meehan, K. B., Siefert, C. J., Haggerty, G., Sexton, J., . . Baade, L. (2018). Introduction of the DSM-5 levels of Personality Functioning Questionnaire. Personality Disorders, 9, 553-563. https://doi.org/10.1037/per0000264

Hutsebaut, J., Feenstra, D. J., \& Kamphuis, J. H. (2016). Development and preliminary psychometric evaluation of a brief self-report questionnaire for the assessment of the DSM-5 level of Personality Functioning Scale: The LPFS brief form (LPFS-BF). Personality Disorders, 7, 192-197. https://doi.org/10.1037/per0000159

Keyes, C. L. (2005). Mental illness and/or mental health? Investigating axioms of the complete state model of health. Journal of Consulting and Clinical Psychology, 73(3), 539-548. https://doi.org/10.1037/0022-006X.73.3.539

Krueger, R. F., Derringer, J., Markon, K. E., Watson, D., \& Skodol, A. E. (2012). Initial construction of a maladaptive personality trait model and inventory for DSM-5. Psychological Medicine, 42, 1879-1890.

https://doi.org/10.1017/S0033291711002674

Krueger, R. F., Eaton, N. R., Clark, L. A., Watson, D., Markon, K. E., Derringer, J., . . Livesley, J. (2011). Deriving an empirical structure of personality pathology for DSM-5. Journal of Personality Disorders, 25(2), 170-191. https://doi.org/10.1521/pedi.2011.25.2.170

Livesley, W. J. (2009). General assessment of personality disorder (GAPD). Toronto, Canada: Sigma Assessment Systems.

Lorenzo-Seva, U., \& Ferrando, P. J. (2013). FACTOR 9.2. A Comprehensive program for fitting exploratory and semiconfirmatory factor analysis and IRT models. Applied Psychological Measurement, 37(6), 497-498. https://doi.org/10.1177/0146621613487794

Lupano Perugini, M. L., de la Iglesia, G., \& Castro Solano, A. (2017). The Mental Health Continuum-Short Form (MHC-SF) in the Argentinean context: Confirmatory factor analysis and measurement invariance. Europe's Journal of Psychology, 13(1), 93-108. https://doi.org/10.5964/ejop.v13i1.1163

Maples, J. L., Carter, N. T., Few, L. R., Crego, C., Gore, W. L., Samuel, D. B., . . Miller, J. D. (2015). Testing whether the DSM-5 personality disorder trait model can be measured with a reduced set of items: An item response theory investigation of the personality inventory for DSM-5. Psychological Assessment, 27(4), 1195-1210. https://doi.org/10.1037/pas0000120

Markon, K. E., Quilty, L. C., Bagby, R. M., \& Krueger, R. F. (2013). The development and psychometric properties of an informant-report form of the personality inventory for DSM-5 (PID-5). Assessment, 20(3), 370-383. https://doi.org/10.1177/1073191113486513

Morey, L. C. (2017). Development and initial evaluation of a Self-Report Form of the DSM-5 Level of Personality Functioning Scale. Psychological Assessment, 29(10), 1302-1308. https://doi.org/10.1037/pas0000450

Morey, L. C., Berghuis, H., Bender, D. S., Verheul, R., Krueger, R. F., \& Skodol, A. E. (2011). Toward a model for assessing level of personality functioning in DSM-5, Part II: Empirical articulation of a core dimension of personality pathology. Journal of Personality Assessment, 93, 347-353. https://doi.org/10.1080/00223891.2011.577853 
Muthén, B., \& Kaplan, D. (1985). A comparison of some methodologies for the factor analysis of non-normal Likert variables. British Journal of Mathematical \& Statistical Psychology, 38, 171-189.

https://doi.org/10.1111/j.2044-8317.1985.tb00832.x

Nelson, S. M., Huprich, S. K., Meehan, K. B., Siefert, C., Haggerty, G., Sexton, J., . . Jackson, J. (2018). Convergent and discriminant validity and utility of the DSM-5 Levels of Personality Functioning Questionnaire (DLOPFQ): Associations with medical health care provider ratings and measures of physical health. Journal of Personality Assessment, 100(6), 671-679. https://doi.org/10.1080/00223891.2018.1492415

Siefert, C. J., Sexton, J., Meehan, K., Nelson, S., Haggerty, G., Dauphin, B., \& Huprich, S. (2019). Development of a short form for the DSM-5 Levels of Personality Functioning Questionnaire. Journal of Personality Assessment. https://doi.org/10.1080/00223891.2019.1594842

Soto, C. J., \& John, O. P. (2017). The next Big Five Inventory (BFI-2): Developing and assessing a hierarchical model with 15 facets to enhance bandwidth, fidelity, and predictive power. Journal of Personality and Social Psychology, 113, 117-143. https://doi.org/10.1037/pspp0000096

SPSS. (2009). PASW Statistics for Windows (Version 18.0) [Computer software]. Chicago, IL, USA: SPSS.

Stanton, J. M., Sinar, E. F., Balzer, W. K., \& Smith, P. C. (2002). Issues and strategies for reducing the lenght of self-report scales. Personnel Psychology, 55(1), 167-194. https://doi.org/10.1111/j.1744-6570.2002.tb00108.x

Stover, J. B., Castro Solano, A., \& Fernández Liporace, M. M. (2019). Dysfunctional personality traits: Its relationship with Five Factor Model, adaptation and symptomatology in a community sample from Buenos Aires. Research in Psychotherapy, 22, 281-291. https://doi.org/10.4081/ripppo.2019.343

Weekers, L. C., Hutsebaut, J., \& Kamphuis, J. H. (2019). The Level of Personality Functioning Scale-Brief Form 2.0: Update of a brief instrument for assessing level of personality functioning. Personality and Mental Health, 13(1), 3-14. https://doi.org/10.1002/pmh.1434

Zimmermann, J., Benecke, C., Bender, D. S., Skodol, A. E., Schauenburg, H., Cierpka, M., \& Leising, D. (2014). Assessing DSM-5 level of personality functioning from videotaped clinical interviews: A pilot study with untrained and clinically inexperienced students. Journal of Personality Assessment, 96, 397-409. https://doi.org/10.1080/00223891.2013.852563

Zimmermann, J., Böhnke, J. R., Eschstruth, R., Mathews, A., Wenzel, K., \& Leising, D. (2015). The latent structure of personality functioning: Investigating criterion a from the alternative model for personality disorders in DSM-5. Journal of Abnormal Psychology, 124, 532-548. https://doi.org/10.1037/abn0000059

Zimmermann, J., Kerber, A., Rek, K., Hopwood, C. J., \& Krueger, R. F. (2019). A brief but comprehensive review of research on the alternative DSM-5 Model for personality disorders. Current Psychiatry Reports, 21, Article 92. https://doi.org/10.1007/s11920-019-1079-z 


\section{Appendix}

Table A1

Personality Functioning Scale (Spanish Version, 28 items)

\begin{tabular}{|c|c|c|c|c|}
\hline Frase & $\begin{array}{c}\text { Completamente } \\
\text { falso }\end{array}$ & $\begin{array}{l}\text { Un poco } \\
\text { verdadero }\end{array}$ & $\begin{array}{c}\text { Bastante } \\
\text { verdadero }\end{array}$ & $\begin{array}{c}\text { Completamente } \\
\text { verdadero }\end{array}$ \\
\hline
\end{tabular}

1. Casi ningún vínculo cercano termina bien

2. A veces me cuesta diferenciar entre lo que opino yo, y lo que los otros esperan que yo piense

3. A pesar de que trato, no logro mantener ninguna relación exitosa y duradera

4. Tengo dificultades para fijar metas personales

5. Me interesa muy poco establecer vínculos cercanos

6. Mayormente actúo sobre el momento, en vez de enfocarme en metas a largo plazo.

7. Las relaciones cercanas me ponen en un lugar vulnerable, y es por eso no vale la pena arriesgarse

8. Generalmente, o me siento muy bien, o me siento o muy mal conmigo mismo/a

9. Solo podría establecer un vínculo cercano con alguien que pueda reconocer y responder a mis necesidades

10. Me cuestas dar un paso atrás y valorar objetivamente mi vida

11. No puedo tolerar cuando las diferencias de opinión son muy marcadas

12. No estoy seguro de cuáles son los estándares que me he fijado a mí mismo

13. No tengo idea de por qué la gente hace lo que hace

14. La mayoría de las cosas que hago son reacciones a lo que hacen los otros

15. No suelo tener muchas interacciones positivas o agradables con las personas

16. Mis emociones cambian rápidamente

17. No presto demasiada atención, o no me importa demasiado, el efecto que mis acciones puedan tener en otras personas

18. Mis estándares personales suelen cambiar bastante dependiendo de las circunstancias

19. No entiendo en absoluto cuales son las intenciones de las personas

20. Los estándares que me fijo para mí mismo suelen ser: o demasiado altos, o demasiado bajos

21. Mucha gente de mi alrededor tiene intenciones dañinas

22. Hay partes de mi personalidad que no encajan bien entre sí, son muy distintas

23. Las relaciones son principalmente una fuente de dolor y sufrimiento

24. Cuando algo no me sale, me suelo sentir enojado o avergonzado de mis habilidades.

25. A veces me resulta fácil no dar importancia al impacto que mis acciones tienen sobre los otros

26. Cuando tengo éxito, suelo sentirme como un impostor

27. Cuando estoy en desacuerdo con alguien, normalmente no sirve demasiado intentar ver las cosas desde su perspectiva

28. Cuando las personas están descontentas conmigo, me es difícil mantener mis emociones bajo control. 